RESEARCH ARTICLE

\title{
Extent of Participation of Farm Youth in Chrysanthemum Cultivation
}

\section{Denadyalan S*1, Murugan P P1 ${ }^{1}$, Shibi Sebastian ${ }^{1}$ and Patil S G ${ }^{2}$}

${ }^{1}$ Department of Agricultural Extension \& Rural Sociology, Tamil Nadu Agricultural University, Coimbatore-641 003

${ }^{2}$ Department of Physical Sciences and Information Technology, Tamil Nadu Agricultural University, Coimbatore-641 003.

\begin{abstract}
Youthification of the farming population has the potential to revive, reform, and revolutionize the agriculture and allied sectors by concentrating the youth's efforts towards it. Chrysanthemum is a traditional flower crop with many economic importance and numerous avenues for value addition and export. The study was conducted among 120 farm youths in Omalur, Kadayampatti, and Mecheri blocks of Salem district, Tamil Nadu.An ex post facto research design was used to study the extent of participation and factors that contribute to the participation of farm youth in chrysanthemum cultivation. Analysis of the responses indicated that a majority of farm youth had a medium (71.66 per cent) level of participation and 19.16 per cent had a high level of participation. Statements with a higher mean score, such as availability of cultivable land (4.16), attractive remuneration (4.09), agricultural knowledge (3.90), and interest in agriculture and allied activities (3.89), were the key contributing factors that led to the increased participation of farm youth in chrysanthemum cultivation.
\end{abstract}

Keywords: Chrysanthemum; factors; farm youth; participation.

\section{INTRODUCTION}

According to the annual report of the Ministry of Youth Affairs and Sports (2019-20), India has one of the world's youngest populations, with roughly 65 per cent of the population under the age of 35 years. Youth aged 15 to 29 years make up 27.5 per cent of the population and represent one out of every four people. The age bracket 16-30 years was considered as 'youth' by the National Youth Policy of 2012.

In contrast to the rest of the world, India's youth bulge poses two challenges: 1 . the country's numerically outstripping young population must be adequately quenched with access to education; 2. the working-age population has to be provided with newer employment prospects. To meet the employment requirements of youth, there is a need to diversify employment opportunities and entrepreneurship development by adding value and innovating the indigenous sectors like agriculture and related activities. Since India is predominantly an agrarian economy, it must channel its resources through effective programmes and policies to meet the needs of the youth, agriculture sector, and the country as a whole.

Floriculture is a sector with a lot of untapped potential and new job opportunities for the youth. According to the APEDA, the area under floriculture production was $3,05,000$ ha in India during 2019-
20 , with a production of $23,01,000$ MT of loose flowers and 7,62,000 MT of cut flowers, India's total floriculture export was Rs. 575.98 crores (77.84 USD million) in 2020-21. India is the world's second-largest flower-growing country after China, and it ranks $14^{\text {th }}$ in terms of floriculture exports, which accounts for only 0.40 per cent share of global floriculture exports in 2018, which could be attributed to gaps in maintaining international quality standards, a lack of integrated cold chain management, unorganized market and distribution networks (Nikhila et al. 2021). Major floriculture centres have emerged in Maharashtra, Karnataka, Andhra Pradesh, Haryana, Tamil Nadu, Rajasthan, and West Bengal. Tamil Nadu is currently India's leading flower producer with 4,61,711 MT during the year 2019-20 (Department of Horticulture and Plantation crops of Tamil Nadu).

"Queen of the East," chrysanthemum of the Asteraceae family, is a popular ornamental plant used as cut flowers, loose blooms, and pot plants eyes are in high demand during the festive season. Secondary metabolites, such as dyes, floral scents, and pyrethrums, can be extracted from chrysanthemum, making it a commercially viable, climate-resilient, and multipurpose flower crop. To meet the requirements of the flourishing flower export centres, value addition units, and extraction units, the crop must be produced continuously and sustainably.

$107 \mid 10-12$ | 1 
The Salem district historically has a substantial area covered under the chrysanthemum. According to the Department of Horticulture and Plantation crops of Tamil Nadu, the district had 1143 hectares under chrysanthemum cultivation, with a production of $20574 \mathrm{MT}$ and productivity of $18 \mathrm{MT} / \mathrm{Ha}$ in the year 2018-19. Climate suitability, less intensive with considerable remuneration were the reasons for the spread of the crop. Farmers select cultivars based on local demand and sell them in local markets. Chrysanthemum is not cultivated year-round, which was one of the main reasons for the absence of export or viable value-addition or extraction units. Youth participation in agriculture activities has been linked to their economic motivation, scientific orientation, and risk orientation, implying that their involvement will lead to innovations and the discovery of new avenues and opportunities in the sector (Varsha Chouhan, 2018). In this context, the present study was carried out with the objectives to ascertain the extent of the participation of farm youth and to find the factors responsible for the participation of farm youth in chrysanthemum cultivation.

\section{MATERIAL AND METHODS}

An ex post facto research design was adopted and the study was carried out in the Salem district of Tamil Nadu. A sample size of 120 farm youths was selected for the study with ten respondents from each village, using snow ball sampling. The top three blocks Omalur, Kadayampatti, and Mecheri and four villages from each block having the highest area under chrysanthemum cultivation were purposively selected.

The extent of participation in chrysanthemum cultivation among farm youth refers to an individual's level of participation in various farming activities, obtained on a three-point continuum scale: regularly, occasionally, and not at all, developed by Martal (2019) with slight modifications. Factors that were responsible for the participation of farm youth in chrysanthemum cultivation were obtained on a 5-point likert scale, following the scale developed by Rashmi Chaudhary et al. (2018) with slight modifications. Descriptive statistics were used for analyzing the data collected.

\section{RESULTS AND DISCUSSION}

The extent of the participation of farm youth in chrysanthemum cultivation

The extent of participation of farm youth refers to the individual's participation in various farming activities such as variety selection, ploughing, irrigation, spraying of chemicals, pinching, ratooning, grading, packing of flowers, selection of mandi/seller and marketing in chrysanthemum cultivation. Data on the participation of farm youth in chrysanthemum cultivation was gathered, and they were divided into three categories based on their participation score, following the cumulative frequency method. Figure 1 represents the distribution of rural youth by their level of participation in chrysanthemum cultivation. Among the farm youth surveyed, a majority (71.66 per cent) of them had a medium level of participation, 19.16 per cent had a high level, followed by 9.16 per cent with a low level of participation in chrysanthemum cultivation. Factors that are responsible for their participation in chrysanthemum cultivation are discussed below. Most of the farm youth had medium to high levels of participation (90.82 per cent), which was in accordance with the findings of Martal (2018) and Suman Verma (2019).

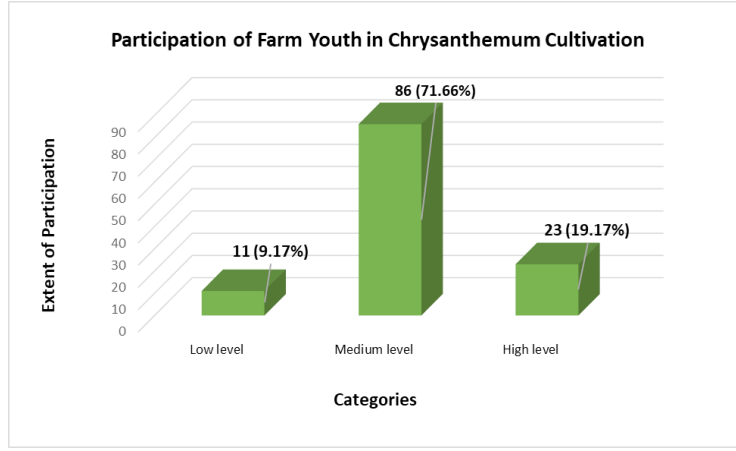

Fig 1. Distribution of farm youth by their level of participation in chrysanthemum cultivation

\section{Factors responsible for the participation of farm} youth in chrysanthemum cultivation

Factors responsible for the participation of farm youth in chrysanthemum cultivation according to their mean value are depicted in Figure 2. The most critical factor responsible for the participation of farm youth in chrysanthemum cultivation was the availability of cultivable land with a mean value of 4.16. Land that is cultivable and fertile cannot be left unproductive unless there is a pressing reason to do so. As a result, it acts as a motivator for farm youth to participate in chrysanthemum cultivation.

The second most important factor responsible for the participation of farm youth in chrysanthemum cultivation was its attractive remuneration with a mean score of 4.09. The flowers fetch higher prices during the festive season and most of the farmers target their harvest during this season, with higher demand and localized markets offering fair prices for the farmers.

Other contributing factors are agricultural knowledge, interest in agriculture and allied activities with a mean score of 3.90 and 3.89 leads to farm youth's active participation in cultivation. 
Youths raised in farming families have a natural affinity for farming and related activities and looking forward to capitalising on their existing agricultural knowledge and experience.

Lack of job alternatives with a mean score of 3.67 has been cited as a major factor contributing to the youths' return to agriculture. Unemployment caused by the COVID-led lockdown forced them to look for alternative and long-term employment in agriculture and allied activities in rural areas.
Chrysanthemum is a commercial flower crop that blooms from the third month onwards, up to six or eight months, with average productivity of twenty tonnes per hectare. Chrysanthemum's fertilizer requirement, water requirements and incidence of pests and diseases were much lower than other commercial flower crops. Further, the intensity of care and management was far less, providing youth free time to invest it in other productive economic activities. Thus, the respondents gave a mean score of 3.61 for the statement less intensive cash crop.

\section{Factors Responsible for Participation of Farm Youths in Chrysanthemum Cultivation}

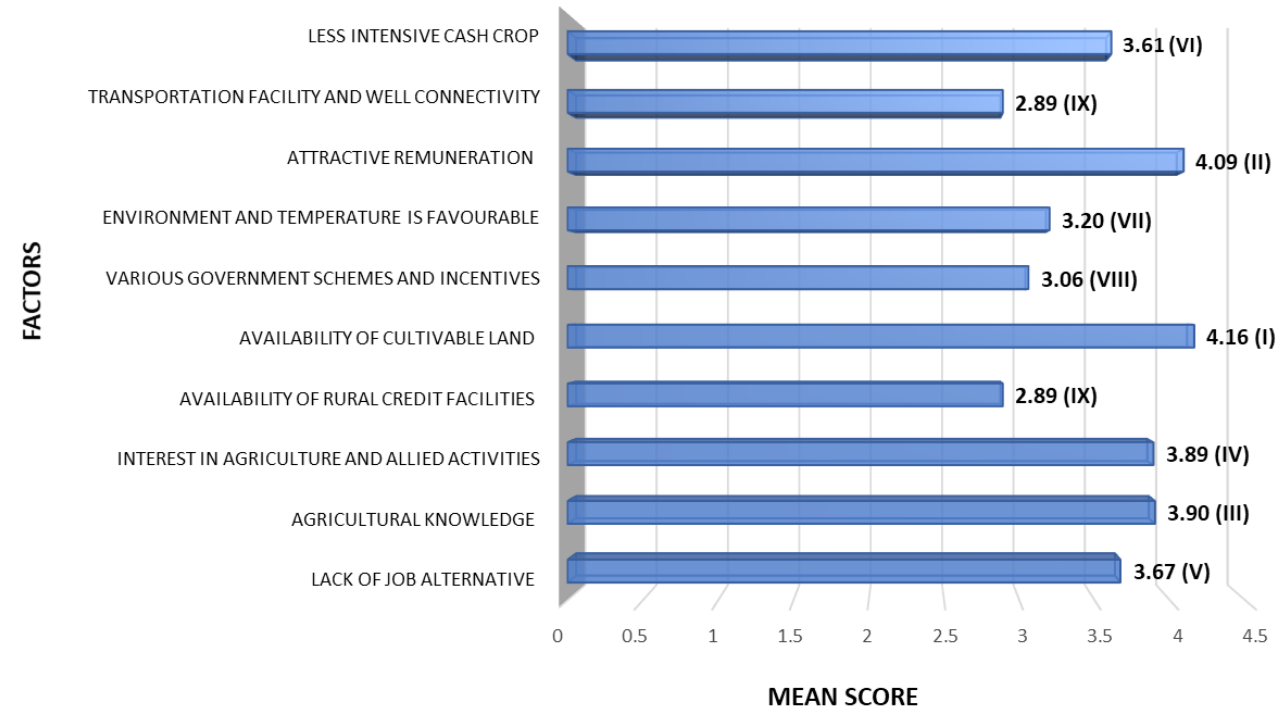

Fig 2. Factors responsible for the participation of farm youths in chrysanthemum cultivation

Though the crop's water requirement is moderate, short and intense rainfall followed by dry spells induced by climate change were not suitable for the crop leading to delays in planting and harvesting, which were planned for the festive season. Hence, the statement environment and temperature are favorable got a mean score of 3.20.

Chrysanthemum is primarily grown only in a few blocks of the district, and the government's shift in focus on other horticultural crops such as vegetables and fruits has left the chrysanthemum behind, as evidenced by the statement "various government schemes and incentives" with a mean score of 3.06.

Chrysanthemum is not covered under crop insurance schemes and has a much lower chance of receiving institutional or formal credit than other food and commercial crops. Farmers struggle to get fair remunerative prices for the harvest during peak season; since the produce is perishable and bulkier, it poses numerous challenges for the farmer to transport the harvested flowers to other major markets such as Krishnagiri, Madurai, and Koyambedu. The outcome of which, the statements transportation facilities, well connectivity and availability of rural credit facilities received a mean score of 2.89 from the respondents, which was in accordance with the findings of Rashmi Chaudhary et al. (2018).

\section{CONCLUSION}

When the entire economy is stressed due to COVID lockdown, rural youths have returned to agriculture, the only sector that had positive growth during the pandemic. Sectors, such as IT and manufacturing, were the most benefited from the participation of the younger generation. Diversion of youth's efforts, knowledge, exposure, and innovation into agriculture shows promising signs for the sector's future growth. Youths participation could benefit commercial floriculture crops like chrysanthemum having untapped economic potential. Higher scientific orientation, rapid learning, and innovativeness of today's youth would be the icing on the cake for rural 
enterprises. With the help of government policies and programmes supplemented by the guidance of NGOs and extension agencies, youth's interests and energy can be retained in agriculture.

\section{REFERENCES}

Anshu Rani and Rampal V.K., 2016. Involvement of rural youth in agricultural activities in Ludhiana District of Punjab. Intl Jrnl of Agri Res., 50: 528 - 534

Martal, P.B., 2018. Participation of Rural Youth in Agricultural Activities in Sindhudurg District, $M$. Sc. (Agri)

Thesis (unpub.). Dr. BSKKV, Ratnagiri.

Nikhila V.A., Ranjit Kumar, 2021, Floriculture sector in India: current status and export potential, Agricultural Reviews., 673-680

Rashmi Chaudhary, Yasmin Janjhua, Nikhil Sharma, Deepika Sharma, Ankit Pathania and Krishan Kumar., 2019. Factors Determining Rural Youth Participation in Agriculture-Based Livelihood
Activities: A Case Study of Karsog in Himachal Pradesh. Intrntl Jrnl of Economic PInts., 6(2):085089.

Suman Verma., 2019. Participation of Rural Youth in Agricultural Activities in Panagar Block of Jabalpur District of Madhya Pradesh, M. Sc. (Agri) Thesis (unpub.). JNKVV, Jabalpur.

Varsha Chouhan., 2018. Participation of Rural Youth in Agricultural Activities of Madhya Pradesh, M. Sc. (Agri) Thesis (unpub.), JNKVV, Jabalpur.

MYAS, Gol (2019), annual report 2019-20. retrieved from https://yas.nic.in/sites/default/files/ MYAS\%20Annual\%20Report\%20English_2019-20. pdf

Area and Production of Tamil Nadu for 2018-19 (Final Estimates) report by Department of Horticulture and Plantation crops of Tamil Nadu

Website apeda.gov.in accessed on 15.09.2021 and retrieved from http://apeda.gov.in/apedawebsite/ six_head_product/floriculture.htm 